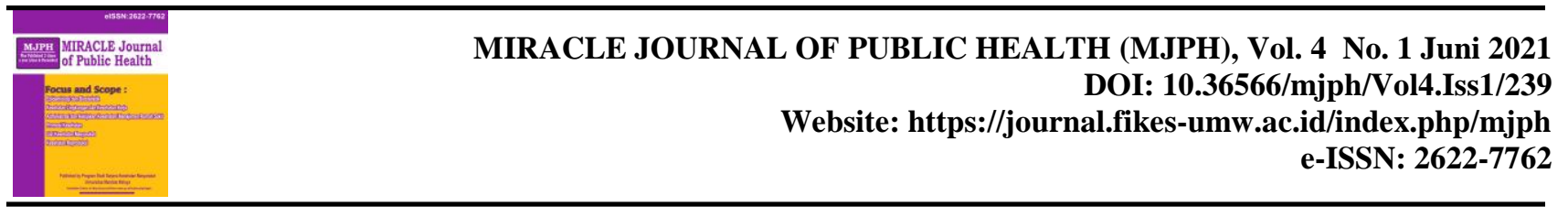

Hubungan Mutu Pelayanan Kesehatan dengan Loyalitas Pasien di Rumah Sakit Bhayangkara Kendari

\title{
Relationship of Quality Health Service Towards Loyalty of Patient at Bhayangkara Hospital Kendari
}

\author{
Andi Mauliyana, Nurul Aisyiah Rizal \\ Program Studi S1 Kesehatan Masyarakat, Universitas Mandala Waluya \\ (andimauliyana.kesmas@gmail.com, 085288839708)
}

\begin{abstract}
ABSTRAK
Berdasarkan profil Rumah Sakit Bhayangkara Kendari, jumlah kunjungan pasien unit rawat inap tersebut dari tahun 2017-2018 mengalami kenaikan jumlah kunjungan pasien. Tujuan penelitian ini untuk mengetahui hubungan mutu pelayanan kesehatan terhadap loyalitas pasien rawat inap di Rumah Sakit Bhayangkara Kota Kendari. Penelitian ini menggunakan desain penelitian Cross-Sectional Study dengan populasi 358 orang dan sampel sebanyak 78 orang yang ditentukan dengan pengambilan sampel menggunakan metode accidental sampling. Analisis data menggunakan uji Chi-Square. Hasil penelitian menunjukkan bahwa ada hubungan pada bukti fisik $\left(X^{2}\right.$ hitung $\left.=4,197 ; \varphi=0,264\right)$, kehandalan $\left(X^{2}\right.$ hitung $\left.=5,816 ; \varphi=0,305\right)$, pada empati $\left(X^{2}{ }_{\text {hitung }}=9,442\right.$; $\varphi=0,378)$. Kesimpulanya, ada hubungan lemah antara bukti fisik, kehandalan, dan empati dengan loyalitas pasien rawat inap di Rumah Sakit Bhayangkara Kota Kendari. Disarankan pihak rumah sakit agar lebih memperhatikan kenyamanan ruangan pasien dan meningkatkan keterampilan dalam melayani pasien sehingga menimbulkan kualitas pelayanan terhadap pasien dan mendorong pasien datang berobat di Rumah Sakit Bhayangkara Kota Kendari.
\end{abstract}

Kata kunci: Mutu pelayanan kesehatan, loyalitas pasien

\section{ABSTRACT}

Based on the Profile of the Bhayangkara Kendari Hospital, the number of patient visits to the inpatient unit from 2017-2018 experienced an increase in the number of patient visits. The purpose of this study was to determine the relationship between the quality of health services and the loyalty of inpatients at the Bhayangkara Hospital, Kendari City. This study used a cross-sectional study design with a population of 358 people and a sample of 78 people who were determined by taking the sample using the accidental sampling method. Data analyze using chi square test. The results showed that there was relationship between physical evidence $\left(X_{\text {count }}^{2}=4,197 ; \varphi=0,264\right)$, reliability $\left(X_{\text {count }}^{2}=5,816 ; \varphi=0,305\right)$, and empathy $\left(X_{\text {count }}^{2}=9,442\right.$; $\varphi=0,378)$ with inpatient loyalty. The conclusion is there was a weak relationship between physical evidence, reliability, and empathy with inpatient loyalty at the Bhayangkara Hospital Kendari City. The hospital should pay more attention to the comfort of the patient's room and improve skills in serving patients so that it can improve the quality of service to patients and encourages patients to come back for treatment at Bhayangkara Hospital Kendari City.

Keywords: Health quality service, patient loyalty

Article Info:

Received: 29 April 2021 | Revised form: 21 Mei 2021 Accepted: 26 Juni 2021 | Published online: 30 Juni 2021 


\section{PENDAHULUAN}

Pelayanan kesehatan yang tepat guna, nyaman serta berkualitas dengan ketersediaan sumber daya merupakan ciri pelayanan kesehatan yang baik menurut World Health Organization (WHO). ${ }^{1}$ Tercapainya pembangunan kesehatan dapat dilihat dari terpenuhinya kebutuhan penerima pelayanan kesehatan seperti adanya sumber daya manusia, fasilitas dan anggaran yang memadai, tenaga kesehatan yang melaksanakan tugasnya dengan penuh tanggung jawab, serta mempunyai keahlian dalam melayani masyarakat sesuai dengan Standar Operasional Prosedur (SOP) yang digunakan di rumah sakit dalam memberikan pelayanan berkualitas agar memberikan dampak positif terhadap kepuasan pasien. $^{2}$

Rumah Sakit Bhayangkara Kendari adalah salah satu Rumah Sakit Umum tingkat III di Kota Kendari dengan status tipe $\mathrm{C}$ dengan jumlah tempat tidur 85. Jumlah personil di RS Bhayangkara Kendari sebanyak 195 orang. Rumah Sakit Bhayangkara Kendari juga menyediakan pelayanan medis IGD 24 jam, Poli Umum, Poli Gigi dan Poli Spesialis terdiri atas Poli Urologi, Poli Interna, Poli Jantung, Poli Saraf, Poli Mata, Poli THT, Poli Kandungan, Poli Anak, Poli Kulit dan Kelamin, Poli Bedah Umum, Poli Unkologi dan Poli Paru. Berdasarkan Profil Rumah Sakit Bhayangkara Kendari dari data tiga tahun terakhir, kunjungan pasien rawat inap dari tahun 2016 sebanyak 4.883 pasien, tahun 2017 sebanyak 4.524 pasien dan tahun 2018 sebanyak 5.289 pasien, jadi jumlah keseluruhan sebanyak 14.696 pasien. Memperhatikan jumlah kunjungan pasien unit rawat inap tersebut dari tahun 2017-2018 mengalami kenaikan jumlah kunjungan pasien. ${ }^{3}$

Penelitian sebelumnya yang dilakukan oleh Artika Sekar Ningrum, Junaid dan Wa Ode Sitti Nurzalmaria yang meneliti hubungan kualitas pelayanan terhadap loyalitas pasien, dimana hasil penelitian tersebut menyimpulkan bahwa kualitas pelayanan berkaitan erat dengan faktor penampilan fisik, empati, keterandalan dan aspek jaminan terhadap loyalitas pasien. Rasa pusa yang dirasakan oleh pasien sangat berhubungan terhadap kualitas pelayanan tenaga medis yang ada di rumah sakit. Kepuasaan pasien bergantung pada perlakukan perawat maupun dokter kepada pasien. Hal ini menjadi salah satu faktor penting dalam melihat mutu pelayanan yang baik yang dibutuhkan oleh pasien. Pasien sebagai pengguna jasa yang ditawarkan rumah sakit menilai rumah sakit dengan memberikan tanggapan tentang puas taua tidak puasnya mereka. Hal ini memperlihatkan kenyataan terkait mutu pelayanan rumah sakit tersebut. ${ }^{4}$

Saat memutuskan mendatangi suatu rumah sakit, calon pasien mengharapkan mendapatkan pelayanan yang baik dari rumah sakit. Namun setelah merasakan pelayanan rumah sakit yang didatangi, pasien akan membandingkan dengan harapan yang mereka inginkan. Terlebih lagi jika pasien pernah mendapatkan pelayanan yang lebih bagus di rumah sakit lain yang pernah didatangi sebelumnya. Pengalaman yang buruk akibat pelayanan yang tidak memuaskan akan berdampak pada ketidapuasaan yang secara langsung membuat pasien tidak ingin lagi kembali ke rumah sakit tersebut. Selain itu ada juga orang enggan 
untuk berobat ke rumah sakit karena lunturnya kepercayan mereka terhadap rumah sakit. Oleh sebab itu tenaga medis maupun para medis yang ada di rumah sakit harus profesional dan membenahi pelayanan terhadpa pasien. Hal tersebut sangat diperlukan guna memberi yang terbaik dan berkualitas kepada pasien agar mendapatkan kepuasaan. Berdasarkan latar belakang di atas, peneliti tertarik melakukan penelitian yang bertujuan untuk melihat hubungan mutu pelayanan terhadap loyalitas pasien rawat inap di Rumah Sakit Bhayangkara Kendari”.

\section{BAHAN DAN METODE}

Studi ini menggunakan metode kuantitatif dengan rancangan Cross-Sectional Study. Studi ini dilakukan sejak bulan Januari hingga Agustus 2020 di Rumah Sakit Bhayangkara Kota Kendari. Populasi studi adalah pasien rawat inap yang dirawat di Rumah Sakit Bhayangkara Kendari periode Januari-April tahun 2020 sebanyak 358 responden, dan sampel sebanyak 78 responden. Cara sampling menggunakan teknik accidental sampling. Pengumpulan data menggunakan kuesioner. Analisis data menggunakan uji ChiSquare, kemudian data disajikan dalam bentuk tabel distribusi frekuensi disertai dengan narasi.

\section{HASIL}

Karakteristik responden terdiri atas umur, jenis kelamin, pendidikan, dan pekerjaan. Distribusi responden menurut umur pada Tabel 1 menunjukkan bahwa dari 78 responden, terbanyak adalah umur 41-50 tahun yaitu sebesar 34,6\% dan yang terkecil adalah usia $>50$ tahun yaitu sebesar
11,5\%. Berdasarkan jenis kelamin jenis kelamin perempuan $(60,3 \%)$ lebih banyak daripada yang berjenis kelamin laki-laki $(39,7 \%)$.

Tabel 1. Distribusi Frekuensi berdasarkan Karakteristrik Responden di Rumah Sakit Bhayangkara Kota Kendari

\begin{tabular}{ccc}
\hline Karakteristrik & N & \% \\
\hline $\begin{array}{c}\text { Kelompok Umur } \\
\text { (Tahun) }\end{array}$ & & \\
$21-30$ tahun & 19 & 24,4 \\
$31-40$ tahun & 23 & 29,5 \\
$41-50$ tahun & 27 & 34,6 \\
> 50 tahun & 9 & 11,5 \\
\hline Jenis Kelamin & & \\
Laki-Laki & 31 & 39,7 \\
Perempuan & 47 & 60,3 \\
\hline Pendidikan & & \\
SD & 7 & 9 \\
SMP & 25 & 32,1 \\
SMA & 37 & 47,4 \\
Perguruan Tinggi & 9 & 11,5 \\
\hline Pekerjaan & & \\
PNS & 20 & 25,6 \\
Pensiunan & 10 & 12,8 \\
Wiraswasta & 33 & 42,3 \\
Petani & 2 & 2,6 \\
Tidak bekerja & 13 & 16,7 \\
\hline Jumlah & $\mathbf{7 8}$ & $\mathbf{1 0 0 , 0}$ \\
\hline Sumb : Data Primer & &
\end{tabular}

Sumber : Data Primer, 2020

Distribusi responden menurut pendidikan pada juga dapat dilihat pada Tabel 1, dimana pendidikan SMA terbanyak dibandingkan yang lain yaitu sebanyak 37 responden $(47,4 \%)$ dan sebian kecil merupakan responden berpendidikan SD yaitu sebanyak 7 responden (9\%). Dari segi pekerjaan menunjukkan bahwa dari 78 responden, hamper sebagiannya bekerja sebegai wiraswasta yaitu 33 responden $(42,3 \%)$ dan yang terkecil adalah Petani $(2,6 \%)$. Distribusi frekuensi terkait loyalitas pasien yakni dari keseluruhan responden, terdapat sebagian kecil responden mengatakan tidak loyal yaitu 23 responden $(29,5 \%)$. 
Tabel 2. Distribusi Frekuensi Berdasarkan Loyalitas Pasien, Bukti Fisik, Kehandalan, Daya Tanggap, Jaminan dan Empati Responden di Rumah Sakit Bhayangkara Kota Kendari

\begin{tabular}{ccc}
\hline Variabel & N & \% \\
\hline $\begin{array}{c}\text { Loyalitas Pasien } \\
\text { Tidak loyal }\end{array}$ & 23 & 29,5 \\
Loyal & 55 & 70,5 \\
\hline Bukti Fisik & & \\
Kurang & 58 & 74,4 \\
Cukup & 20 & 25,6 \\
\hline Kehandalan & & \\
Kurang & 57 & 73,1 \\
Cukup & 21 & 26,9 \\
\hline Daya Tanggap & & \\
Kurang & 54 & 69,2 \\
Cukup & 24 & 30,8 \\
\hline Jaminan & & \\
Kurang & 40 & 51,3 \\
Cukup & 38 & 48,7 \\
\hline Empati & & \\
Kurang & 52 & 66,7 \\
Cukup & 26 & 33,3 \\
\hline Jumlah & $\mathbf{7 8}$ & $\mathbf{1 0 0 , 0}$ \\
\hline
\end{tabular}

Sumber : Data Primer, 2020

Tabel 2 juga menampilkan distribusi responden berdasarkan tangibility (bukti fisik) sebagian besar responden mengatakan kurang sebanyak 58 responden $(74,4 \%)$. Berdasarkan realibility (kehandalan) sebagian besar responden mengatakan kurang yaitu 57 responden $(73,1 \%)$. Distribusi responden berdasarkan responsiveness menunjukkan bahwa dari 78 responden, sebagain besar responden mengatakan kurang yaitu 54 responden $(69,2 \%)$. Berdasarkan assurance (Jaminan), Sebagian besar responden mengatakan kurang yaitu 40 responden (51,3\%). Berdasarkan emphaty (empati), Sebagian besar responden mengatakan kurang yaitu 52 responden $(66,7 \%)$.

Distribusi hubungan bukti fisik (tangibles) dengan loyalitas pasien rawat inap pada Tabel 3 menunjukkan bahwa dari 55 responden $(70,5 \%)$ yang memiliki bukti fisik cukup, diperoleh 10 responden (50\%) yang loyal dan 45 responden $(77,6 \%)$ yang tidak loyal. Selanjutnya dari 23 responden $(29,5 \%)$ yang memiliki bukti fisik kurang, 10 responden (50\%) yang loyal dan 13 responden $(22,4 \%)$ yang tidak loyal. Uji ChiSquare menghasilkan nilai $\mathrm{X}^{2}{ }_{\text {hitung }}=4,197>$ $\mathrm{X}_{\text {tabel }}=3,841$, artinya ada hubungan antara bukti fisik dengan loyalitas pasien rawat inap di Rumah Sakit Bhayangkara Kota Kendari. Dari hasil uji kekuatan hubungan dengan koefisien $\varphi$ (phi) $=0,264$, bermaka adanya hubungan yang lemah antara bukti fisik dengan loyalitas pasien.

Distribusi hubungan kehandalan (reliability) dengan loyalitas pasien rawat inap pada Tabel 3 menunjukkan bahwa dari 78 responden terdapat 55 responden $(70,5 \%)$ yang memiliki kehandalan cukup dan 23 responden $(29,5 \%)$ yang memiliki kehandalan kurang. Dari 55 responden $(70,5 \%)$ yang memiliki kehandalan cukup terdapat 10 responden $(47,6 \%)$ yang loyal dan 45 responden $(78,9 \%)$ yang tidak loyal. Selanjutnya dari 23 responden $(29,5 \%)$ yang memiliki kehandalan kurang terdapat 11 responden $(52,4 \%)$ yang loyal dan 12 responden $(21,1 \%)$ yang tidak loyal. Hasil uji statistik diperoleh nilai $X^{2}{ }_{\text {hitung }}=5,816>$ $\mathrm{X}_{\text {tabel }}=3,841$, berarti terdapat hubungan antara kehandalan dengan loyalitas pasien rawat inap di Rumah Sakit Bhayangkara Kota Kendari. Dari hasil uji kekuatan hubungan dengan koefisien $\varphi$ (phi) $=0,305$, bermaka adanya hubungan yang lemah antara kehandalan dengan loyalitas pasien. 
Tabel 3. Analisis Hubungan Mutu Pelayanan Kesehatan terhadap Loyalitas Pasien Rawat Inap di Rumah Sakit Bhayangkara Kota Kendari

\begin{tabular}{|c|c|c|c|c|c|c|c|}
\hline \multirow{3}{*}{ Variabel } & \multicolumn{4}{|c|}{ Loyalitas Pasien } & \multicolumn{2}{|c|}{ Jumlah } & \multirow{3}{*}{ Uji Statistik } \\
\hline & \multicolumn{2}{|c|}{ Loyal } & \multicolumn{2}{|c|}{ Tidak Loyal } & \multirow{2}{*}{$\mathbf{n}$} & \multirow{2}{*}{$\%$} & \\
\hline & n & $\%$ & $\mathrm{n}$ & $\%$ & & & \\
\hline \multicolumn{8}{|l|}{ Bukti Fisik } \\
\hline Cukup & 10 & 50 & 45 & 77,6 & 55 & 70,5 & \multirow{3}{*}{$\begin{array}{c}X^{2} \text { hit. }=4,197 \\
X^{2} \text { tab. }=3,841 \\
\text { Phi }=0,264\end{array}$} \\
\hline Kurang & 10 & 50 & 13 & 22,4 & 23 & 29,5 & \\
\hline Total & 20 & 25,6 & 58 & 74,4 & 78 & 100,0 & \\
\hline \multicolumn{7}{|l|}{ Kehandalan } & \multirow{4}{*}{$\begin{array}{c}\mathrm{X}^{2} \text { hit. }=5,816 \\
\mathrm{X}^{2}{ }_{\text {tab. }}=3,841 \\
\text { Phi }=0,305\end{array}$} \\
\hline Cukup & 10 & 47,6 & 45 & 78,9 & 55 & 70,5 & \\
\hline Kurang & 11 & 52,4 & 12 & 21,1 & 23 & 29,5 & \\
\hline Total & 21 & 26,9 & 57 & 73,1 & 78 & 100,0 & \\
\hline \multicolumn{7}{|l|}{ Daya Tanggap } & \multirow{4}{*}{$\begin{array}{l}\mathrm{X}^{2}{ }_{\text {hit. }}=1,700 \\
\mathrm{X}^{2}{ }_{\text {tab. }}=3,841\end{array}$} \\
\hline Cukup & 14 & 58,3 & 41 & 75,8 & 55 & 70,5 & \\
\hline Kurang & 10 & 41,7 & 13 & 24,1 & 23 & 69,2 & \\
\hline Total & 24 & 30,8 & 54 & 69,2 & 78 & 100,0 & \\
\hline \multicolumn{7}{|l|}{ Jaminan } & \multirow{4}{*}{$\begin{array}{l}X^{2} \text { hit. }=0,718 \\
X^{2}{ }_{\text {tab. }}=3,841\end{array}$} \\
\hline Cukup & 29 & 76,3 & 26 & 65 & 55 & 70,5 & \\
\hline Kurang & 9 & 23,7 & 14 & 35 & 23 & 29,5 & \\
\hline Total & 38 & 48,7 & 40 & 51,3 & 78 & 100,0 & \\
\hline \multicolumn{7}{|l|}{ Empati } & \multirow{4}{*}{$\begin{array}{c}\mathrm{X}^{2}{ }_{\text {hit. }}=9,442 \\
\mathrm{X}^{2} \text { tab. }=3,841 \\
\text { Phi }=0,378\end{array}$} \\
\hline Cukup & 12 & 46,2 & 43 & 82,7 & 55 & 70,5 & \\
\hline Kurang & 14 & 53,8 & 9 & 17,3 & 23 & 29,5 & \\
\hline Total & 26 & 33,3 & 52 & 66,7 & 78 & 100,0 & \\
\hline
\end{tabular}

Sumber : Data Primer, 2020

Distribusi hubungan daya tanggap (responsiveness) dengan loyalitas pasien rawat inap pada Tabel 3 menunjukkan bahwa dari 55 responden $(70,5 \%)$ yang memiliki daya tanggap cukup, 14 responden $(58,3 \%)$ yang loyal dan 41 responden $(75,8 \%)$ yang tidak loyal. Selanjutnya dari 23 responden $(29,5 \%)$ yang memiliki daya tanggap kurang, 10 responden $(41,7 \%)$ yang loyal dan 13 responden $(24,1 \%)$ yang tidak loyal. Hasil uji statistik diperoleh nilai $X_{\text {hitung }}=1,700<X_{\text {tabel }}$ $(3,841)$, berarti tidak ada hubungan antara daya tanggap dengan loyalitas pasien rawat inap di Rumah Sakit Bhayangkara Kota Kendari.
Distribusi hubungan jaminan (assurance) dengan loyalitas pasien rawat inap pada Tabel 3 menunjukkan bahwa dari 55 responden $(70,5 \%)$ yang memiliki jaminan cukup, 29 responden (76,3\%) yang loyal dan 26 responden (65\%) yang tidak loyal. Selanjutnya dari 23 responden $(29,5 \%)$ yang memiliki jaminan kurang, 9 responden $(23,7 \%)$ yang loyal dan 14 responden (35\%) yang tidak loyal. Hasil uji statistik diperoleh nilai $\mathrm{X}_{\text {hitung }}=0,718<\mathrm{X}_{\text {tabel }}=3,841$. yang bermakna artinya tidak ada hubungan antara jaminan dengan loyalitas pasien rawat inap di Rumah Sakit Bhayangkara Kota Kendari. Distribusi hubungan empati (emphaty) 
dengan loyalitas pasien rawat inap pada Tabel 3 menunjukkan bahwa dari 55 responden $(70,5 \%)$ yang memiliki empati cukup, 12 responden $(46,2 \%)$ yang loyal dan 43 responden $(82,7 \%)$ yang tidak loyal. Selanjutnya dari 23 responden (29,5\%) yang memiliki empati kurang, 14 responden $(53,8 \%)$ yang loyal dan 9 responden $(17,3 \%)$ yang tidak loyal. Hasil uji statistik diperoleh nilai $\mathrm{X}_{\text {hitung }}=9,442>\mathrm{X}_{\text {tabel }}=3,841$, bermakna terdapat hubungan antara empati dengan loyalitas pasien rawat inap di Rumah Sakit Bhayangkara Kota Kendari. Dari hasil uji kekuatan hubungan diperoleh nilai koefisien $\varphi$ (phi) $=0,378$ yang berarti lemahnya hubungan antara jaminan dengan loyalitas pasien.

\section{PEMBAHASAN}

Bukti fisik ditunjukkan oleh sikap petugas kesehatan berupa keramahan dan kesopanan saat melayani pasien, serta adanya perhatian akan kelengkapan perlatan serta situasu nyaman yang disedikan di rumah sakit. Karena sikap tersebut jika diterapkan oleh tenaga medis kepada pasien, maka bisa menimbulkan rasa puas pada pasien akan pelayanan yang didaptkan dari petugas kesehatan. Kelengkapan fasilitas sarana dan prasarana di rumah sakit akan menumbuhkan kemauan pasien untuk datang lagi untuk berobat. Penelitian ini menemukan bahwa terdapat hubungan antara bukti fisik terhadap loyalitas pasien. Studi ini juga menemukan bahwa pelayanan yang berkualitas membawa dampak besar terhadap loyalitas atau kesetiaan pasien.

Berdasarkan hasil penelitian pada Tabel 3 menunjukkan bahwa ternyata ditemukan juga responden yang menyetakan bukti fisik cukup namun mereka tidak loyal. Hal tersebut bisa terjadi karena beberapa faktor diantaranya tidak sesuainya pelayanan yang diberikan seperti perawat atau dokter yang kurang ramah dan ruangan yang panas tidak terdapat kipas angina atau pendingin ruangan. Hal ini tentunya menjadi salah satu penyebab pasien masih kurang sesuai dengan loyalitas di Rumah Sakit Bhayangkara Kota Kendari. Selanjutnya juga terdapat 10 responden (50\%) yang memilih bukti fisik kurang namun loyal. Hal ini disebabkan oleh beberapa petugas selalu menjaga penampilan serta perlengkapan peralatan medis yang digunakan sudah sesuai dengan loyalitas.

Hasil penelitian ini didukung oleh penelitian yang dilakukan Ertika Sekar Ningrum yang mengatakan bahwa ada hubungan antara faktor bukti fisik dalam pelayan kesehatan dengan loyalitas pasien. Dari hasil penelitian ini dapat disimpulkan bahwa apabila bukti fisik yang diberikan kurang baik, sopan, ramah dan memiliki sarana yang kurang, maka pasien cenderung merasa tidak puas dan tidak sesuai dengan loyalitas yang mereka inginkan. Berbanding terbalik dengan jika pelayanan yang diberikan baik, sopan, ramah dan memiliki fasilitas yang lengkap maka pasien akan merasa sesuai dengan loyalitas yang diinginkan. Oleh sebab itu, peneliti merekomendasikan perlunya kesadaran setiap pegawai rumah sakit untuk memberikan pelayanan yang terbaik dan melengkapi fasilitas yang diperlukan pasien.

Komponen ini memperlihatkan kekuatan rumah sakit dalam melayani pasien secara tepat, 
terampil, terpercaya, serta memiliki tanggung jawab terhadap apa yang ditawarkan, bukan sekedar janji kosong serta. Secara umum dimensi ini mencerminkan kesesuaian serta kehandalan dari suatu kapasitas organisasi. ${ }^{5}$

Penelitian ini menunjukkan ada hubungan yang lemah antara kehandalan dengan loyalitas pasien di Rumah Sakit Bhayangkara Kota Kendari. Berdasarkan hasil penelitian ditemukan ada responden yang mengatakan kehandalan cukup namun tidak loyal. Hal ini di sebabkan oleh beberapa faktor di antaranya waktu pelayanan perawat yang tidak tepat waktu dan jadwal pelayanan rumah sakit belum tepat dilaksanakan. Hal ini tentuya menjadi salah satu penyebab pasien merasa kurang sesuai dengan loyalitas pasien di Rumah Sakit Bhayangkara Kota Kendari. Selanjutnya juga terdapat 11 responden $(52,4 \%)$ yang memilih kehandalan kurang namun loyal. Hal ini di sebabkan oleh beberapa faktor yaitu dalam memberikan informasi yang jelas dan mudah di mengerti, prosedur pelayanan tidak berbelit-belit dan petugas kesehatan selalu ada di tempat saat pasien membutuhkan pertolongan sehingga sudah sesuai dengan loyalitas pasien.

Hasil penelitian ini sejalan dengan penelitian yang dilakukan Ertika Sekar Ningrum (2016) yang mengatakan bahwa ada hubungan antara kualitas pelayanan berdasarkan aspek keterandalan dengan loyalitas pasien. Dari hasil penelitian ini dapat disimpulkan bahwa jika perawat ataupun petugas kesehatan yang lain tidak tepat waktu dalam pelayanan, maka dalam hal ini pasien merasa tidak sesuai dengan loyalitas yang diberikan. Berbanding terbalik apabila petugas kesehatan memberikan pelayanan kepada pasien tepat waktu dan jadwal pelayanan rumah sakit dijalan dengan tepat, maka pasien akan merasa sesuai dengan loyalitas yang diinginkan. Oleh sebab itu, peneliti merekomendasikan perlunya kesadaran setiap petugas agar melayani pasien tepat waktu, agar para pasien mendapatkan kepuasan dari pelayanan yang diberikan dan akan datang kembali untuk bisa merasakan pelayan terbaik lagi di rumah sakit tersebut tanpa.

Daya tanggap ialah segala aktivitas tenaga medis yang melakukan pelayanan terhadap pasien, dimana dikala pasien mulai masuk untuk mendapatkan pertolongan, ketika pasien kritis, saat pasien harus mendapatkan tindakan medis serta saat perawat terampil dan tepat. Hasil penelitian ini menunjukkan bahwa tidak ada hubungan antara daya tanggap dengan loyalitas pasien di Rumah Sakit Bhayangkara Kota Kendari. Berdasarkan hasil penelitian terdapat responden yang mengatakan daya tanggap cukup namun tidak loyal, hal ini disebabkan oleh berapa faktor diantaranya pemberian informasi yang tidak jelas dan tidak dimengerti, tindakan yang kurang cepat pada saat membutuhkan pelayanan, serta ketanggapan dan kecepatan dalam memberikan pelayanan tidak sesuai. Selanjutnya juga terdapat 10 responden $(41,7 \%)$ yang memilih daya tanggap kurang namun loyal. Hal ini di sebabkan oleh beberapa faktor yaitu kemampuan dokter dan perawat dalam menyelesaikan keluhan sudah tepat dan pasien tidak menunggu lama untuk mendapatkan pelayanan. Hasil penelitian ini tidak sejalan dengan penelitian yang dilakukan oleh A. Joy M. Rattu (2018) yang berjudul 
Hubungan Antara Mutu Pelayanan Dengan Kepuasan Pasien di Poliklinik Penyakit Dalam Rumah Sakit Umum Gmim Pancaran Kasih Manado menemukan ada hubungan antara penilaian daya tanggap dengan kepuasan pasien rawat inap di Poliklinik Penyakit Dalam Rumah Sakit Umum GMIM Pancaran Kasih Manado yaitu semakin tanggap pelayanan maka penilaian pasien/klien rawat jalan terhadap pelayanan asuhan keperawatan akan semakin puas pula. ${ }^{6}$

Dari hasil penelitian ini dapat disimpulkan bahwa apabila petugas kesehatan melayani pasien dengan lamban dan memberikan informasi yang tidak jelas maka dalam hal ini pasien tidak merasa sesuai dengan loyalitas yang diinginkan. Berbanding terbalik apabila petugas kesehatan melayani pasien dengan cepat dan memberikan informasi yang jelas maka dalam hal ini pasien akan merasa sesuai dengan loyalitas yang diinginkan. Oleh sebab itu, peneliti merekomendasikan perlunya kesadaran setiap petugas dalam memberikan tanggapan cepat seperti melakukan dengan cepat saat perawat di panggil untuk mengganti infus.

Jaminan meliputi pengetahuan dan sopan santun serta kemampuan dalam menanmkan kepercayaan kepada pelanggan. Pengetahuan serta keterampilan, keramahan memberikan pelayanan kesehatan mencerminkan suatu jaminan pelayanan yang baik. Jaminan yang ditawarkan sebuah rumah sakit menuntuk tenaga medis untuk berinteraksi dengan pasien sesuai dengan SOP yang telah ditetapkan sehingga pasien merasa nyaman dan aman ketika ditangani. Keamanan mencerminkan pelanggan bahwa ia bebas dari bahaya risiko dan keraguan. Penelitian ini menemukan bahwa tidak terdapat hubungan antara jaminan dan loyalitas pasien di Rumah Sakit Bhayangkara Kota Kendari. Hasil penelitian ini menemukan responden yang mengatakan jaminan cukup namun tidak loyal, hal ini disebabkan karena petugas kurang memberikan penjelasan yang akurat berkaitan dengan tindakan keperawatan yang dilakukan. Selanjutnya, terdapat responden yang memilih jaminan kurang namun loyal. Hal ini disebabkan oleh bebrapa faktor seperti petugas memberikan alur pengobatan yang tepat kepada pasien, terampil dalam melakukan tindakan medis serta melakukan pengamatan pada setiap keperawatan yang dilakukan, selain itu jaminan keamanan dan kepercayaan terhadap pelayanan. Hasil penelitian ini sejalan dengan penelitian oleh Nining Hartini (2014) yang mengatakan bahwa tidak ada hubungan yang signifikan antara dimensi jaminan dengan loyalitas pasien RSUD Syekh Yusuf Gowa. ${ }^{7}$ Namun, hasil ini bertolak belakang dengan penelitian yang dilakukan oleh Hastuti, dkk., yang menyatakan bahwa ada hubungan antara dimensi mutu assurance dengan kepuasan pasien di Rumah Sakit Umum Daerah Yogyakarta. Hal ini disebabkan karena responden banyak yang tidak mengetahui latar belakang pendidikan perawat yang menanganinya serta petugas kesehatan belum mampu sepenuhnya memberikan kepercayaan kepada pasien. ${ }^{8}$

Dari hasil penelitian ini dapat disimpulkan bahwa apabila petugas petugas memberikan alur pengobatan yang kurang tepat kepada pasien, tidak terampil dalam melakukan tindakan medis 
serta tidak melakukan pengamatan pada setiap keperawatan yang dilakukan, tidak menjamin keamanan dan kepercayaan terhadap pelayanan maka, dalam hal ini pasien tidak akan merasa sesuai dengan loyalitas yang di inginkan, berbanding terbalik apabila petugas kesehatan petugas memberikan alur pengobatan yang tepat kepada pasien, terampil dalam melakukan tindakan medis serta melakukan pengamatan pada setiap keperawatan yang dilakukan, selain itu jaminan keamanan dan kepercayaan terhadap pelayanan maka pasien akan merasa sesuai dengan loyalitas yang diinginkan.

Empati ialah perilaku individu dalam memahami kebutuhan pelanggan. Tindakan tenaga kesehatan yang penuh kesabaran serta rajin saat melayani pasien tanpa pilih-pilih pasien yang satu dengan yang lainnya, bisa menumbuhkan harapan dan rasa puas bagi para pasien. Hasil penelitian ini menunjukkan bahwa ada hubungan antara empati dan loyalitas pasien di Rumah Sakit Bhayangkara Kota Kendari dengan (hubungan lemah). Hasil penelitian didapatkan responden yang mengatakan jaminan cukup namun tidak loyal, hal ini disebabkan karena perawat atau dokter tidak memberikan perhatian khusus kepada pasien, tidak memberikan dorongan kepada pasien serta kurangnya memberikan solusi dalam permasalahan setiap pasien. Selanjutnya, terdapat 14 responden $(53,8 \%)$ yang memilih empati kurang namun berloyalitas. Hal ini disebabkan oleh faktor yaitu menggunakan bahasa yang sopan serta pelayanan kepada semua pasien tanpa memandang status sosial sudah sesuai. Hasil penelitian ini tidak sejalan dengan penelitian Eka
Masi Lumban Toruan (2017) yang mengatakan bahwa tidak terdapat hubungan kepedulian terhadap kepuasan pasien rawat inap Rumah Sakit Pelabuhan Medan. ${ }^{9}$ Namun penelitian ini sejalan dengan penelitian yang dilakukan oleh Nurfardiansyah (2015) dengan hasil uji Spearman's Rho yang menunjukkan adanya hubungan empati/kepedulian dengan kepuasan pasien peserta BPJS di Rumah Sakit Umum Daerah Syekh Yusuf Gowa. ${ }^{10}$

Dari hasil penelitian ini dapat disimpulkan bahwa apabila petugas kesehatan ketika memberikan dorongan dan motivasi yang kurang baik, kurang memberikan solusi dalam permasalahan pasien maka dalam hal ini, pasien tidak akan merasa sesuai dengan loyalitas yang diinginkan, berbanding terbalik jika petugas kesehatan memberikan dorongan atau motivasi serta memberikan solusi dalam permasalahan pasien maka pasien akan merasa sesuai dengan loyalitas yang diinginkan. Oleh sebab itu, peneliti merekomendasikan perlunya kesadaran setiap petugas agar selalu memberikan dorongan atau motivasi setiap pasien yang mendapatkan perawatan di Rumah Sakit Bhayangkara Kota Kendari.

\section{KESIMPULAN DAN SARAN}

Berdasarkan hasil penelitian dan pembahasan dalam penelitian ini, maka dapat ditarik kesimpulan bahwa ada hubungan lemah antara bukti fisik, kehandalan, dan empati dengan loyalitas pasien rawat inap di Rumah Sakit Bhayangkara Kota Kendari. Namun tidak terdapat hubungan antara daya tanggap dan jaminan 
dengan loyalitas pasien rawat inap di Rumah Sakit Bhayangkara Kota Kendari. Berdasarkan kesimpulan di atas, maka disarankan kepada Rumah Sakit Bhayangkara Kota Kendari agar lebih meningkatkan mutu pelayanan kesehatan oleh tenaga kesehatan seperti lebih mengenal pasien, memberikan perhatian kepada pasiennya dan sejauh mana komunikasi dapat terbentuk sehingga pasien dapat merasa nyaman karena diperhatikan, dan merespon secara cepat keluhan pasien di ruang rawat inap. Disarankan kepada peneliti selanjutnya agar melakukan penelitian terkait dengan menambah jumlah responden atau membuat perbandingan antar rumah sakit yang memiliki kesamaan karakteristik.

\section{DAFTAR PUSTAKA}

1. World Health Organization. Hospitals. Geneva: World Health Organization; 2014.

2. Kementerian Kesehatan R. Peraturan Menteri Kesehatan Republik Indonesia Nomor 58 tahun 2014 tentang Standar Pelayanan Kefarmasian di Rumah Sakit. Jakarta: Kementrian Kesehatan RI; 2014.

3. Rumah Sakit Bhayangkara Kendari. Profil Rumah Sakit Bhayangkara Tingkat III Kendari Tahun 2018. Kendari: Rumah Sakit Bhayangkara Kendari; 2019.

4. Junaid J, Nurzalmariah WOS, Ningrum AS. Hubungan Kualitas Pelayanan terhadap Loyalitas Pasien Rawat Inap Umum di
Rumah Sakit Umum Daerah Kota Kendari Tahun 2016. (Jurnal Ilmiah Mahasiswa Kesehatan Masyarakat). 2017;1(3).

5. Parasuraman A, Zeithaml, Valarei, Berry L. Kualitas Pelayanan. Jakarta: Fakultas Kedokteran UI; 2006.

6. Rattu AJM, Pangerapan DT, Palandeng OELI. Hubungan Antara Mutu Pelayanan dengan Kepuasan Pasien di Poliknik Penyakit Dalam Rumah Sakit Umum GMIM Pancara Kasih Manado. JKK (Jurnal Kedokteran Klinik). 2018 Feb 21;2(1):9-18.

7. Hartini N. Pengaruh Kualitas Pelayanan terhadap Kepuasan Pasien RSUD Syekh Yusuf Gowa. [Makassar]: Universitas Islam Negeri Alauddin Makassar; 2014.

8. Hastuti KW, Mudayana AA, Nurdila AP, Hadiyatma D. Hubungan Mutu Pelayanan dengan Kepuasan Pasien Peserta BPJS di Rumah Sakit Umum Daerah Yogyakarta. KesMas: Jurnal Fakultas Kesehatan Masyarakat. 2017;11(2):161-8.

9. Toruan EML. Pengaruh Mutu Pelayanan Kesehatan Terhadap Kepuasan Pasien Rawat Inap di Rumah Sakit Pelabuhan Medan (Prima Husada Cipta) Tahun 2017 [Skripsi]. [Medan]: Universitas Sumatera Utara; 2017.

10. Burhanuddin N. Hubungan Mutu Pelayanan Kesehatan dengan Kepuasan Pasien RSUD Syekh Yusuf Gowa. PERENNIAL. 2016;12(1):41-6. 